\title{
Letters
}

\section{Dementia: things will get worse if we do not act}

In their editorial published in CMAJ, Drs. Stall, Tardif and Sinha presciently highlighted that the $\$ 50$ million in federal funding over 5 years will likely be inadequate to achieve the stated goals of Canada's first national dementia strategy. ${ }^{1}$ This has proven true at the front lines of clinical care. As a clinician providing hospital care for people with dementia, I have been unable to detect any meaningful improvements - rather, things are getting worse, especially in acute care.

Analyses by the Canadian Institute for Health Information ( $\mathrm{Cl} \mathrm{HI}$ ) show that when older adults living with dementia are admitted to hospital, they are $50 \%$ more likely to experience hospital harm and have twice the length of stay of people without dementia. Although dementia once accounted for one-third of alternate level of care (ALC) days, CIHI estimates that this impact has grown and dementia now accounts for almost half of ALC days. ${ }^{2}$

Dementia has become a major contributor to ALC and hospital overcrowding, which has not received appropriate attention to date. All people in Canada are paying the price for this neglect in the form of decreased access to hospital beds. This will, predictably, hamper postpandemic efforts to address the growing wait lists for elective surgeries.

The situation is guaranteed to worsen if we do not act. Dementia-related pressure exerted on hospitals will escalate as the number of people living with dementia grows rapidly and larger numbers present to and are admitted to hospital. Given that Canada has one of the lowest numbers of hospital beds per capita of all Organisation for Economic Co-operation and Development nations, ${ }^{3}$ we can no longer afford to overlook the specialized needs of this vulnerable population in light of its growing impact on hospital bed capacity. Published strategies to address this issue by improving hospital care of persons with dementia have been summarized at www.hospitaldementiacare.ca. ${ }^{4}$
Stall and colleagues were correct in stating that for a national dementia strategy to effect meaningful change, sustained political will and adequate funding will be required. ${ }^{1}$ To this, I would add that our national, provincial and territorial dementia strategies must now include improved care of people with dementia in hospital. Robust acute care strategies for patients with dementia will improve access to hospital beds for people of all ages in Canada.

\section{Frank J. Molnar MDCM MSc}

Specialist in geriatric medicine, University of Ottawa Department of Medicine, Bruyère Research Institute, Ottawa Hospital Research Institute, Ottawa, Ont.

- Cite as: CMAJ 2022 January 24;194:E98. doi: $10.1503 / \mathrm{cmaj} .80550$

\section{References}

1. Stall NM, Tardif P, Sinha SK. Ensuring Canada's first dementia strategy is not shelved and forgotten. CMAJ 2019;191:E851-2.

2. Seniors with dementia more likely to be hospitalized, stay longer in emergency department. Ottawa: Canadian Institute for Health Information; 2018. Available: https://www.cihi.ca/en/ dementia-in-canada/dementia-care-across-the -health-system/dementia-in-hospitals (accessed 2021 Nov. 22).

3. Hospital beds (indicator) [table]. Paris: OECD; 2021. Available: https://data.oecd.org/healtheqt/ hospital-beds.htm (accessed 2021 Nov. 22).

4. Molnar FJ. Hospitals "failing to plan for dementia is planning to fail": all Canadian hospitals must launch acute care dementia strategies if they are serious about decreasing hospital overcrowding, decreasing Alternate Level of Care (ALC), and thereby increasing hospital capacity to permit pandemic recovery and to meet future escalating needs. CGS Journal of CME 2021. Available: www.hospitaldementiacare.ca (accessed 2021 Nov. 22).

Content licence: This is an Open Access article distributed in accordance with the terms of the Creative Commons Attribution (CC BY-NC-ND 4.0) licence, which permits use, distribution and reproduction in any medium, provided that the original publication is properly cited, the use is noncommercial (i.e., research or educational use), and no modifications or adaptations are made. See: https://creativecommons. org/licenses/by-nc-nd/4.0/ 